\title{
Investigation of gravity waves using horizontally resolved radial velocity measurements
}

\author{
G. Stober ${ }^{1}$, S. Sommer ${ }^{1}$, M. Rapp ${ }^{2,3}$, and R. Latteck ${ }^{1}$ \\ ${ }^{1}$ Leibniz-Institute of Atmospheric Physics at the Rostock University, Schlossstr. 6, 18225 Kühlungsborn, Germany \\ ${ }^{2}$ Deutsches Zentrum für Luft- und Raumfahrt, Institut für Physik der Atmosphäre, Oberpfaffenhofen, Germany \\ ${ }^{3}$ Meteorologisches Institut München, Ludwig-Maximilian Universität München, Munich, Germany
}

Correspondence to: G. Stober (stober@iap-kborn.de)

Received: 27 May 2013 - Published in Atmos. Meas. Tech. Discuss.: 25 June 2013

Revised: 4 September 2013 - Accepted: 26 September 2013 - Published: 30 October 2013

\begin{abstract}
The Middle Atmosphere Alomar Radar System (MAARSY) on the island of Andøya in Northern Norway $\left(69.3^{\circ} \mathrm{N}, 16.0^{\circ} \mathrm{E}\right)$ observes polar mesospheric summer echoes (PMSE). These echoes are used as tracers of atmospheric dynamics to investigate the horizontal wind variability at high temporal and spatial resolution. MAARSY has the capability of pulse-to-pulse beam steering allowing for systematic scanning experiments to study the horizontal structure of the backscatterers as well as to measure the radial velocities for each beam direction. Here we present a method to retrieve gravity wave parameters from these horizontally resolved radial wind variations by applying velocity azimuth display and volume velocity processing. Based on the observations a detailed comparison of the two wind analysis techniques is carried out in order to determine the zonal and meridional wind as well as to measure first-order inhomogeneities. Further, we demonstrate the possibility to resolve the horizontal wave properties, e.g., horizontal wavelength, phase velocity and propagation direction. The robustness of the estimated gravity wave parameters is tested by a simple atmospheric model.
\end{abstract}

\section{Introduction}

The mesosphere/lower thermosphere region (MLT) is characterized by a high temporal and spatial variability due to planetary and gravity waves. Gravity waves (GW) are an important driver of the atmospheric dynamics. They carry energy and momentum from their source regions and deposit them far away from the point of origin, altering the circulation pattern in the middle atmosphere (e.g., Fritts and Alexander, 2003; Becker, 2012).

There are several in situ (e.g., Eckermann and Vincent, 1989; Theuerkauf et al., 2011) and ground-based observation techniques like, e.g., meteor radars (e.g., Hocking, 2005; Fritts et al., 2010b, a; Placke et al., 2011), MF radars (e.g., Hoffmann et al., 2010, 2011; Placke et al., 2013), lidars (e.g., Rauthe et al., 2006; Gerding et al., 2008), airglow imagers (e.g., Nakamura et al., 1999; Pautet and Moreels, 2002; Suzuki et al., 2004, 2010) or CCD images of noctilucent clouds (NLC) (e.g., Pautet et al., 2011) as well as satelliteborne observations (e.g., Preusse et al., 2000; Ern et al., 2004, 2011) to quantify the properties of gravity waves and their effect on the background flow. Here we investigate short-period gravity waves using horizontally resolved radar observations.

MAARSY is dedicated to accessing the horizontal wind variability. The radar is capable to perform pulse-to-pulse beam steering allowing to conduct systematic scanning experiments. During summer 2011 MAARSY was operated employing 97 different beam directions to observe the horizontal variability of polar mesospheric summer echoes (PMSE). Some initial results of the properties of gravity waves using MAARSY multi-beam experiments have been derived from the pure morphology of the observed echoes as discussed in Rapp et al. (2011). In the current paper, the next step to determining the wave properties is taken, that is, the PMSE backscatter (e.g., Rapp and Lübken, 2004) is used as a tracer to deduce the horizontal variability of mesospheric winds by applying a velocity azimuth display analysis (VAD) (Browning and Wexler, 1968) and volume velocity processing (VVP) algorithm (Waldteufel and Corbin, 1979). 
Here we demonstrate that scanning experiments are useful to derive horizontally resolved radial velocity measurements and how these images/snapshots of the horizontal wind variability are analyzed with respect to gravity waves. Further, we evaluate our analysis method with a simple model similar to the approach presented in Fritts et al. (2010a). This model includes a mean background flow and a superposition of two dominant GW. The meridional, zonal and vertical GW amplitudes are coupled by the linear polarization relations for GW. The vertical wavelength is given by the dispersion equation (e.g., Fritts and Alexander, 2003; Suzuki et al., 2010) for short-period GW.

The manuscript is structured as follows. Section 2 contains a short technical description of the radar and the experiment. Section 3 provides an overview over the general PMSE conditions during the observations, including a selected 3-D case of the PMSE structure. In Sect. 4 we present a short introduction of the VAD and VVP technique. The mean wind situation for the investigated period is described in Sect. 5, which includes a comparison of the VAD and VVP wind measurements. Section 6 contains a method to create 2-D radial velocity variation images and how such images can be analysed regarding gravity waves using modelling results. In Sect. 7 we describe our analysis procedure and demonstrate the ability to retrieve GW parameters based on four cases. The results are summarized and discussed in Sect. 8.

\section{MAARSY multi-beam experiments}

MAARSY employs an active-phased array antenna consisting of 433 linearly polarized Yagi antennas. Each of the antennas is connected to its own transceiver module, which is adjustable in power and phase. This design permits to steer the beam on a pulse-to-pulse basis. A more detailed technical description of the radar is presented in Latteck et al. (2010, 2012). Making use of this rapid beam steering capability, MAARSY is able to conduct systematic scanning experiments covering an area of about $80 \mathrm{~km}$ in diameter at mesospheric heights. The number of different beam directions per experiment is mainly given by the required Nyquist frequency to ensure reliable radial velocity measurements. With an increasing off-zenith angle the radial Doppler shift increases as well, due to the horizontal winds.

During summer 2011 MAARSY was operated in a multibeam mode with 97 different beam directions. This was achieved by a sequence of four experiments containing 25 beams each. The vertical beam was included in each experiment, leading to 97 individual and unambiguous beam directions. In Fig. 1 a projection of all 97 beam directions at $85 \mathrm{~km}$ altitude is shown. The black lines indicate the coast line of Northern Norway. The diameter of the red circles corresponds to a beam width of $3.6^{\circ}$. The beam positions for each of the four experiments are shown in Fig. 2.

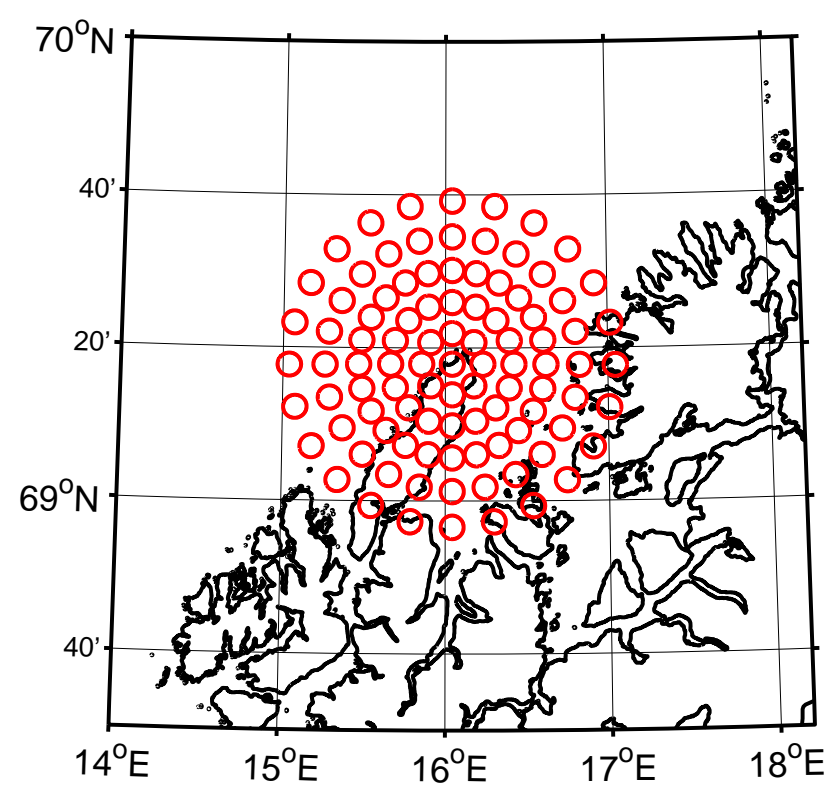

Fig. 1. Beam position of MAARSY scanning experiment during summer 2011. The black contour lines indicate the Northern Norwegian coast line. The red circles represent the beam positions assuming a $3.6^{\circ}$ beam width at $84 \mathrm{~km}$.

In Table 1 the experiment parameters are summarized. The order of the experiments corresponds to the labels of the panels a-d in Fig. 2. In particular, the experiments meso006b25, meso006c 25 and meso006d 25 were designed to be analyzed applying a velocity azimuth display analysis, viz. the radial velocity is measured for 24 different azimuth directions, whereas the zenith angle is kept constant for each of the subexperiments. A critical point in performing such multi-beam experiments is the Nyquist frequency. The PMSE observations are carried out with a pulse repetition frequency (PRF) of $1250 \mathrm{~Hz}$. This PRF avoids any issues with range aliasing effects. On the other hand a higher PRF would be desirable to increase the Nyquist frequency or the corresponding Nyquist velocity, which is equivalent to the highest observable unaliased due to the limited horizontal wind speed.

In particular, the radial velocities for off-zenith angles larger than $10^{\circ}$ could be aliased due to limited Nyquist velocity. Therefore, each radial velocity measurement is checked for a likely aliasing and - if possible - is unwrapped. This is done by computing an initial mean prevailing wind estimate just using the beam directions from experiment meso006a25. The wind is computed by using a straight-forward Doppler Beam Swinging method (DBS). Based on the prevailing zonal and meridional wind it is possible to compute a radial velocity for each beam direction, which is compared to the measured one. By simply adding or subtracting multiples of the Nyquist velocity we unwrap likely aliased radial velocity measurements from the experiments with larger off-zenith 
Table 1. Experiment configuration for all four experiments. The abbreviations stand for: CI - coherent integration, PRF - pulse repetition frequency, IPP - inter-pulse period.

\begin{tabular}{lllll}
\hline Parameter & meso006a25 & meso006b25 & meso006c25 & meso006d25 \\
\hline PRF & $1250 \mathrm{~Hz}$ & $1250 \mathrm{~Hz}$ & $1250 \mathrm{~Hz}$ & $1250 \mathrm{~Hz}$ \\
CI & 2 & 2 & 2 & 2 \\
running time & $21 \mathrm{~s}$ & $21 \mathrm{~s}$ & $21 \mathrm{~s}$ & $21 \mathrm{~s}$ \\
pulse length & $6.67 \mu \mathrm{s}$ & $6.67 \mu \mathrm{s}$ & $6.67 \mu \mathrm{s}$ & $6.67 \mu \mathrm{s}$ \\
pulse code/complementary & $8 \mathrm{bit}$ & $8 \mathrm{bit}$ & $8 \mathrm{bit}$ & $8 \mathrm{bit}$ \\
IPP & $0.8 \mathrm{~ms}$ & $0.8 \mathrm{~ms}$ & $0.8 \mathrm{~ms}$ & $0.8 \mathrm{~ms}$ \\
duty cycle & $2 \%$ & $2 \%$ & $2 \%$ & $2 \%$ \\
sampling start range & $49.8 \mathrm{~km}$ & $49.8 \mathrm{~km}$ & $49.8 \mathrm{~km}$ & $49.8 \mathrm{~km}$ \\
sampling end range & $116.7 \mathrm{~km}$ & $116.7 \mathrm{~km}$ & $116.7 \mathrm{~km}$ & $116.7 \mathrm{~km}$ \\
sampling resolution & $300 \mathrm{~m}$ & $300 \mathrm{~m}$ & $300 \mathrm{~m}$ & $300 \mathrm{~m}$ \\
Nyquist velocity & $17.51 \mathrm{~m} \mathrm{~s}$ & $17.51 \mathrm{~m} \mathrm{~s}$ & $17.51 \mathrm{~m} \mathrm{~s}$ & $17.51 \mathrm{~m} \mathrm{~s}$ \\
off-zenith angles & $0^{\circ}, 5^{\circ}, 10^{\circ}$ & $0^{\circ}, 15^{\circ}$ & $0^{\circ}, 20^{\circ}$ & $0^{\circ}, 25^{\circ}$ \\
\hline
\end{tabular}

a)

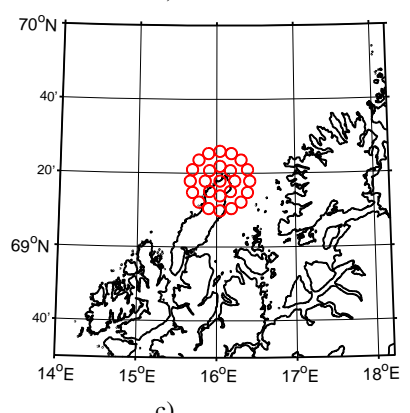

c)

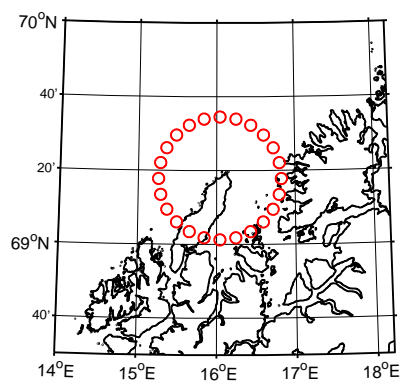

b)

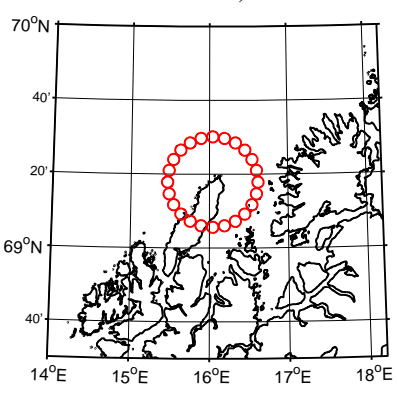

d)

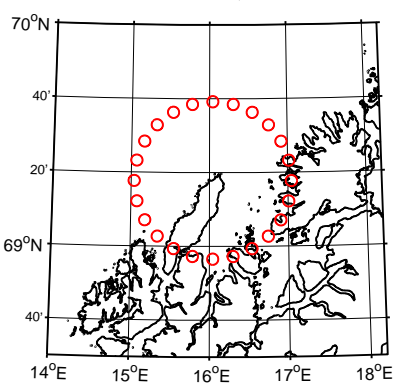

Fig. 2. The multi-beam sequence is conducted using four experiments with 25 beams each. The black contour lines indicate the Northern Norwegian coast line. The red circles represent the beam positions assuming a $3.6^{\circ}$ beam width at $84 \mathrm{~km}$. The labels $\mathrm{a}, \mathrm{b}, \mathrm{c}, \mathrm{d}$ correspond to the experiments meso006a25, meso006b25, meso006c25 and meso006d25 summarized in Table 1.

angles, before we actually apply the different more sophisticated wind analysis techniques.

\section{PMSE observations with MAARSY}

PMSE are a well-known radar backscatter at polar and mid latitudes for VHF radars, indicating a huge variability at various temporal and spatial scales (e.g., Nicolls et al., 2007;

Latteck et al., 2012). Former studies of PMSE investigated the physical processes leading to the formation of this mesospheric backscatter at VHF Bragg wavelengths (see, e.g., Rapp and Lübken, 2004, for a review) or focussed on the issue of the aspect sensitivity of this radar backscatter (e.g., Zecha et al., 2001; Chilson et al., 2002; Smirnova et al., 2010, 2012). There have also been many studies inferring the mesospheric dynamic situation by gaining valuable information about the neutral wind speed and wind variation inside the phenomenon itself (e.g., Zecha et al., 2001; Morris et al., 2006; Nicolls et al., 2010; Dalin et al., 2012; Stober et al., 2012; Nicolls et al., 2012).

Due to the beam steering capabilities of MAARSY it is possible to investigate the wind field in much more detail, applying more sophisticated wind analysis methods such as VAD (Browning and Wexler, 1968) or VVP (Waldteufel and Corbin, 1979). However, these methods require that the strength of the backscatter or at least the accuracy of the radial velocity measurements is rather homogenous inside the observation volume. Therefore, we searched our measurements for strong and long-lasting PMSE events. It turned out that on 20 and 22 July 2011 the strength of the PMSE as well as the vertical extension were stronger compared to the other days during the campaign.

In Fig. 3 the Range-Time-Intensity (RTI) plots of the vertical beam for 20 and 22 July are shown. 21 July is not shown due to a change of experiment leading to a gap during the day. The RTI plots indicate most of the well-known features of PMSE, like, e.g., times with a multiple layer structure or the decreasing PMSE intensity between 16:00 to 17:00 UTC, which are common for the Andenes observations. Further, it is possible to see the modulation of the layers within the PMSE due to GW, which is a well-known feature from previous studies (e.g., Rüster et al., 2001; Chilson et al., 2002; Hoffmann et al., 2008; Chen et al., 2008). Based on these observations of the vertical beam we decided to use $83.4 \mathrm{~km}$ as the reference height for our wind analysis. Further, we took 

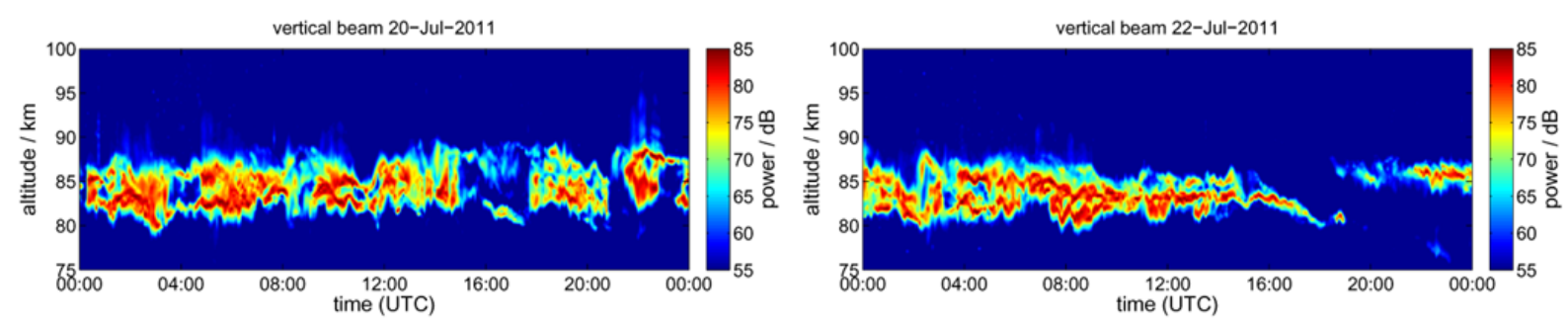

Fig. 3. RTI plots of a PMSE as observed with MAARSY in the vertical beam direction with a vertical resolution of $300 \mathrm{~m}$ and temporal resolution of $5 \mathrm{~min}$. The time is given in UTC.

into account the change of the vertical resolution due to the large off-zenith angle. An off-zenith angle of $25^{\circ}$ in combination with the MAARSY beam width of $3.6^{\circ}$ leads to a vertical smearing of about $2.4 \mathrm{~km}$ at $83.4 \mathrm{~km}$ altitude, although the range resolution is kept the same as for the vertical beam.

Figure 4 shows the 3-D structure of the PMSE for three successive measurements, after interpolating the observations to a Cartesian grid using a cubic spline (Latteck et al., 2012). The image reveals the huge variability of the PMSE intensity on spatial scales of $10-15 \mathrm{~km}$. It seems to be characteristic for the PMSE that the SNR can drop by more than $10-20 \mathrm{~dB}$ within a distance of a few kilometers. As outlined in Hoffmann et al. (2008), short-period GW are a likely cause of this high variability inside the PMSE layer. In particular, the up- and downward motion of the lower edge of the PMSE is likely explained by short-period GW.

\section{VVP and VAD wind analysis to account for horizontal inhomogeneities in the wind field}

Previous studies used different methods to infer the GW properties from the wind field, such as wavelet spectra or hodograph analysis (e.g., Hoffmann et al., 2008; Rapp et al., 2011; Placke et al., 2013). Here we want to make use of multi-beam experiments to reveal the horizontal wind variability due to GW. Following the approach of Browning and Wexler (1968) the wind field can be expressed as a Taylor series for the horizontal wind components consisting of a mean prevailing zonal and meridional wind (labeled by index 0 ) and the first-order gradient terms:

$$
\begin{aligned}
u & =u_{0}+\frac{\partial u}{\partial x} \cdot x+\frac{\partial u}{\partial y} \cdot y \\
\text { and } v & =v_{0}+\frac{\partial v}{\partial x} \cdot x+\frac{\partial v}{\partial y} \cdot y .
\end{aligned}
$$

In Eq. (1) $u$ denotes the zonal and $v$ the meridional wind direction. Transforming the Cartesian coordinates into spherical ones permits to express the radial wind velocity $v_{\text {rad }}$ in dependence of the azimuth $(\phi)$ and zenith $(\theta)$ angle yields:

$$
\begin{aligned}
v_{\text {rad }}(\phi, \theta) & =u \cdot \cos (\phi) \sin (\theta)+v \cdot \sin (\phi) \sin (\theta) \\
& +w \cos (\theta) .
\end{aligned}
$$

The azimuth angle $\phi$ is referenced to the east and measured counterclockwise and $\theta$ refers to the zenith distance. The mean vertical wind velocity $w_{0}$ is assumed to be constant within the measurement volume. Using the approach of Browning and Wexler (1968) in Eq. (2) leads to an expression of the radial velocity in dependence of the mean zonal, meridional and vertical wind and the first-order gradient wind inhomogeneities.

The fact that the number of beam directions is larger than the number of unknowns (right-hand terms in Eq. 1) permits to solve the set of equations using a least squares fit. The major difference between the VAD and VVP method is the way the fitting of the wind field is done. The basic idea of the VAD is to decompose Eq. (2) into its Fourier components (Browning and Wexler, 1968) and fitting for each of the Fourier coefficients, whereas the VVP procedure directly fits the set of equations for all the unknown variables (Waldteufel and Corbin, 1979).

The MAARSY multi-beam experiments were analyzed using both methods. The advantage of a VAD scan is that one needs fewer measurements to gain information about the first-order inhomogeneities. In principle one needs no measurement from inside the scanning area. In the same time as one VVP scan with 97 beams, we can perform four VAD scans. The disadvantage of the VAD technique is that it just uses a small portion of all the information gathered by the 97-beam experiment. Another difficulty of a VAD analysis is that it does not allow to distinguish between the vertical wind velocity and the horizontal divergence inside the scanning volume just using one scan. Following the nomenclature of Browning and Wexler (1968) the first Fourier coefficient $a_{0}$ is given by

$a_{0}=-r \cdot \sin (\theta) \cdot \operatorname{div}_{\mathrm{h}}+2 w_{0} \cdot \cos (\theta)$,

where $r$ denotes the radius of the VAD scanning circle depending on the altitude or range and $\operatorname{div}_{\mathrm{h}}$ is the horizontal divergence. This issue is partly solved by an extended velocity azimuth display (EVAD) (Larsen et al., 1991; Matejka and Srivastava, 1991). Such an analysis combines several VAD scans with different off-zenith angles to distinguish between contributions of the vertical wind velocity and the horizontal divergence. For each of the off-zenith angles one measures 

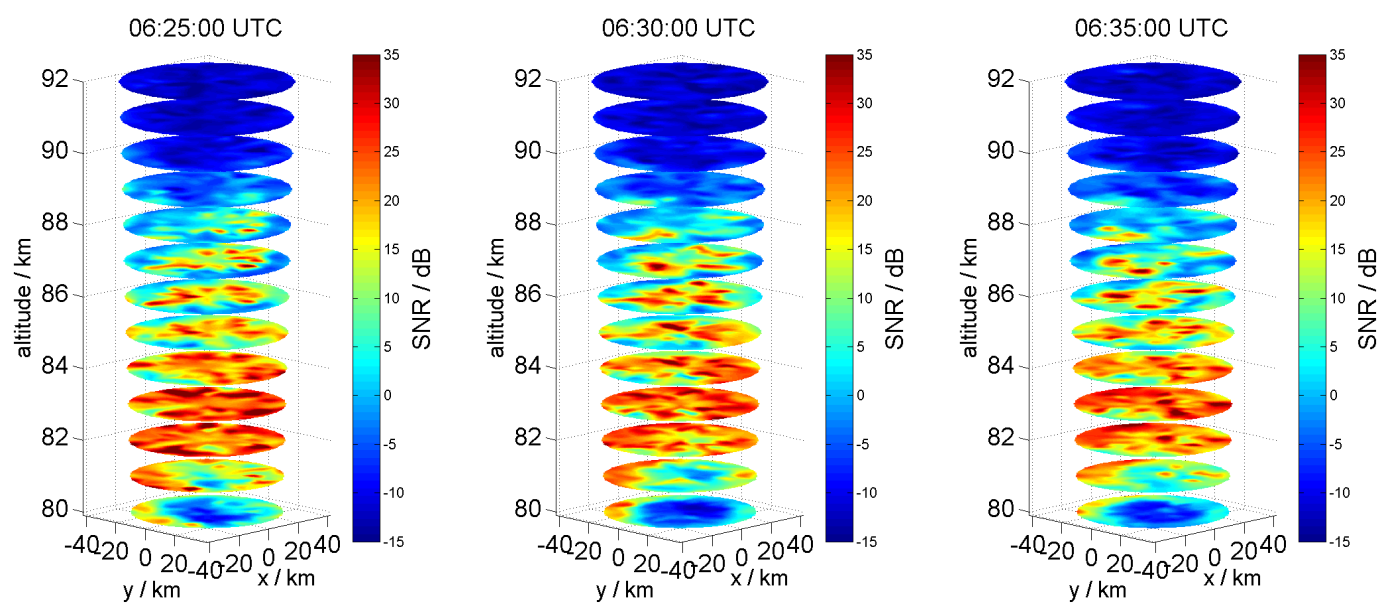

Fig. 4. RTI plots of the 3-D structure of the PMSE for three successive scans from 20 July 2011. The SNR for each beam direction was gridded using a cubic spline. The vertical distance between the horizontal slices is $1 \mathrm{~km}$. The horizontal slices show a significant beam-to-beam as well as the temporal variability.

the coefficient $a_{0}$, which, hence, permits to solve Eq. (3) with respect to the horizontal divergence and the vertical velocity.

By applying a VVP fit, this problem is completely overcome and one gets an unambiguous result for the vertical velocity and the horizontal divergence within the observation volume. In addition the VVP is more robust so as to determine a prevailing mean wind, because the method can better deal with gaps/inhomogeneities of the PMSE backscatter. The VVP technique permits to determine a reliable wind velocity based on $50 \%$ of the available different beam directions, whereas the VAD method tends to be more biased by gaps along the scanning circle caused by the horizontal variability of the PMSE backscatter. A VAD experiment was only analyzed when we had radial wind measurements from 21 different azimuth directions out of the 24 oblique beams along one VAD circle.

\section{VVP and VAD/EVAD wind comparison}

The quasi-simultaneous multi-beam experiment is an ideal possibility to compare both techniques to understand the advantages and disadvantages of both analysis procedures. Before we are going to compare both techniques we will have a look at the background wind situation. In Fig. 5 the determined zonal and meridional wind velocity within the scanning volume is shown. Both days indicate a dominating semi-diurnal tidal structure in both components and a much weaker diurnal tide. The zonal wind component shows a mean westerly flow at the altitude of the PMSE, whereas the meridional wind component indicates a mean southward direction. Concerning the mean winds and the tidal structure both days represent a typical polar summer situation. Note that the vertical structure is mainly dominated by the offzenith beams (zenith angle $>15^{\circ}$ ), which leads to a vertical smearing. The layered structure that can be found in the RTI plots (Fig. 3) of the vertical beam disappears in the analyzed zonal and meridional wind fields due to this vertical smearing effect.

The basic idea of the approach from Browning and Wexler (1968) was to use a Taylor series of the wind field to account for first-order inhomogeneities in the wind field. The MAARSY multi-beam observations are suitable to determine these first-order distortions. In particular, the relation of the horizontal divergence and the vertical velocity should provide some information about the GW activity. In Fig. 6 the computed vertical wind velocity and the horizontal divergence for both days are visualized. The vertical velocity shows values of $\pm 5 \mathrm{~m} \mathrm{~s}^{-1}$, which still seems to be slightly too large as a mean vertical velocity considering the observation volume used here. The highest vertical velocities occur at edges of the PMSE layer and are likely related to relatively large deviations from the nominal off-zenith angle. On the other hand a visual inspection of the color bar demonstrates that the vertical velocity is most of the time close to $0 \mathrm{~m} \mathrm{~s}^{-1}$, which in so far should be a good estimate for such a huge volume. However, similar vertical velocities were observed by Hoppe and Fritts (1995) using the EISCAT. On the other hand there are EISCAT measurements indicating even higher Doppler shifts of about $\pm 10 \mathrm{~m} \mathrm{~s}^{-1}$ (e.g., Fritts et al., 1990; Strelnikova and Rapp, 2011, 2013).

Although it is not possible to identify single gravity waves, these two parameters visualize the high variability of the horizontal wind field and the importance of considering such inhomogeneities, in particular if one uses measurements that have a spatial separation of several kilometers. The first-order distortions permit to estimate how the wind field changes with increasing distance from the radar site. A horizontal gradient in the wind field in the order of $0.5 \times 10^{-3} 1 / \mathrm{s}$ can lead to a $20 \mathrm{~m} \mathrm{~s}^{-1}$ change of the total wind velocity at a 

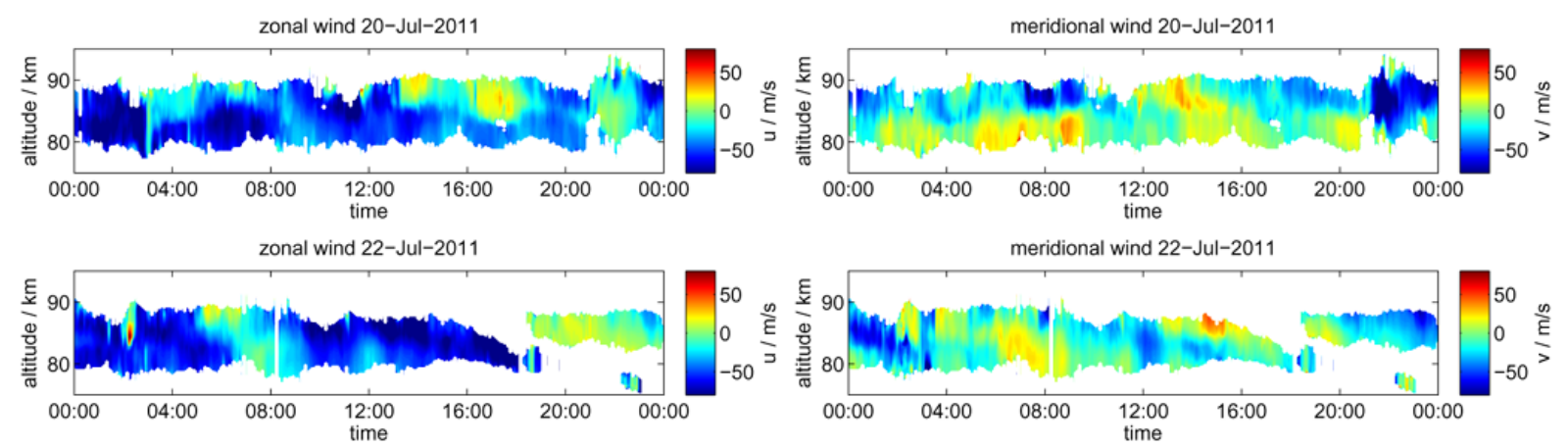

Fig. 5. Observed zonal and meridional wind from MAARSY measurements using PMSE as tracer for 20 and 22 July 2011 . The time is given in UTC.
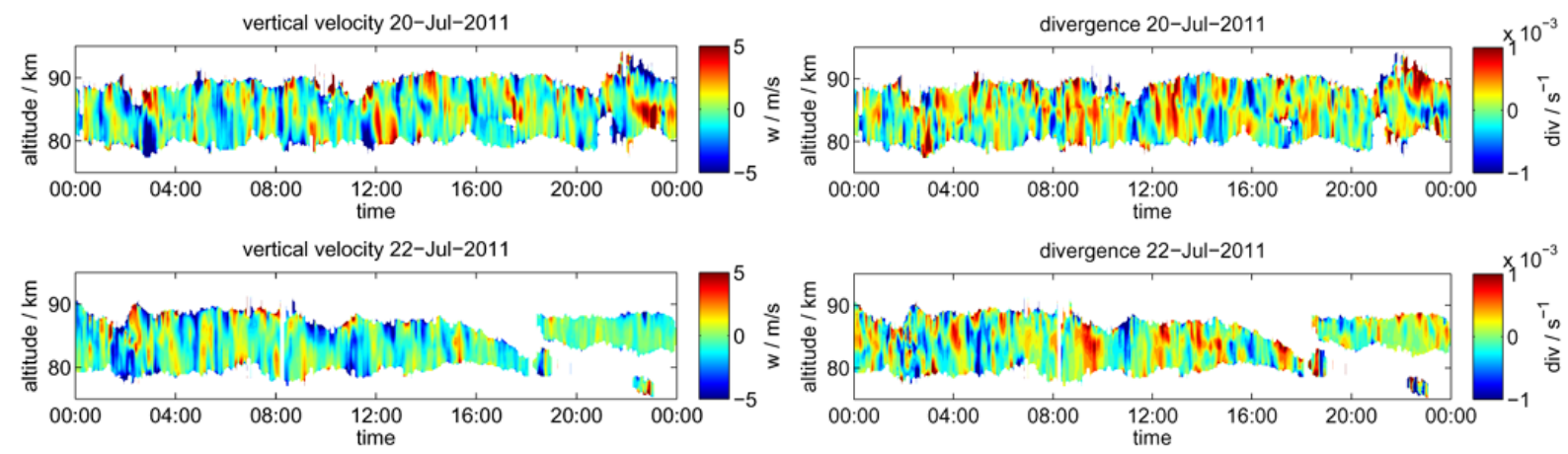

Fig. 6. Observed vertical and horizontal divergence wind from MAARSY measurements using PMSE as tracer for 20 and 22 July 2011 . The time is given in UTC.

horizontal distance of $40 \mathrm{~km}$. Hence, it can be of importance to consider these horizontal differences, in particular if the measurement volumes are not completely coincident. This should be considered if one aims to compare different wind observation techniques that employ different beam pointing directions or are spatially separated (e.g., lidar, meteor radars, satellite).

To get a first impression of how well both methods compare with each other, the observations were analyzed applying the VVP technique using all available beam directions and VAD scans for three different off-zenith angles. To avoid any difficulties with edge effects, only the observations from an altitude of $83.4 \mathrm{~km}$ were considered. The scatter plots of VAD vs. VVP are shown in Fig. 7. The correlation coefficient and the number of data points are given by the capital letters $R$ and $N$, respectively. The red line indicates the slope 1 regression and one black line is given by a linear fit to the scatter plot. The second black line is computed after swapping the $\mathrm{x}$ and $\mathrm{y}$ axes.

The comparison also includes some measurements from 21 July 2011. Figure 7 clearly visualizes that the correlation between both methods increases with increasing off-zenith angle. The best agreement is achieved between the VVP and VAD analysis for the $25^{\circ}$ off-zenith angle. However, there is still a reasonable agreement for the $5^{\circ}$ off-zenith VAD scan and the VVP technique. This comparison provides two essential results: the VVP and the VAD analysis result in similar horizontal wind speeds as long as the volumes are the same, viz. the VVP horizontal wind components are dominated by the largest off-zenith angle using the MAARSY beam positions. The second point is that this comparison directly provides a first idea of the horizontal variability of the wind field. The increased scattering of the $5^{\circ}$ off-zenith VAD scan vs. the VVP is likely caused by GW with horizontal wavelengths much shorter than the VVP scanning diameter. In the absence of such small-scale distortions the scatter plots should look almost identical, like for the $25^{\circ}$ off-zenith angles.

Further, it is not very difficult to combine several VAD scans to an EVAD analysis to resolve the ambiguity between horizontal divergence and vertical velocity. In Fig. 8 the scatter plots of the vertical wind velocity and horizontal divergence for EVAD vs. VVP are shown. The correlation coefficients still indicate a generally reasonable agreement for both parameters. The major difference is that the VVP tends to systematic higher values for the vertical wind velocity and horizontal divergence. Based on the available data it is not possible to judge which method provides the more reliable 

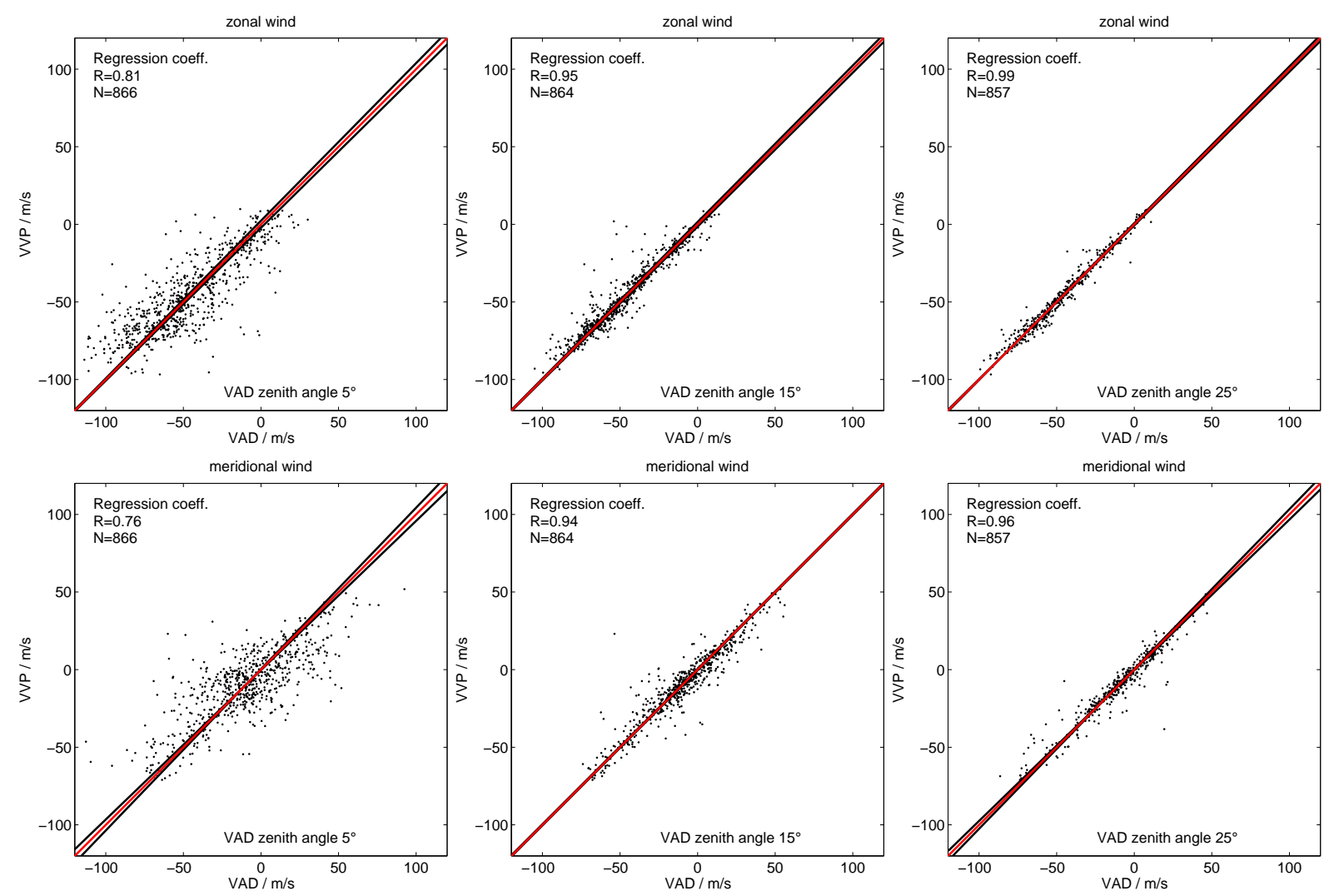

Fig. 7. Scatter plots and correlation coefficients of the zonal and meridional wind determined by a VVP and a VAD analysis including also the available data from 21 st of July. The zenith angle of the VAD analysis of each scatter plot is given in the right lower part. The correlation coefficient and the number of data points are given by the capital letters $R$ and $N$, respectively.
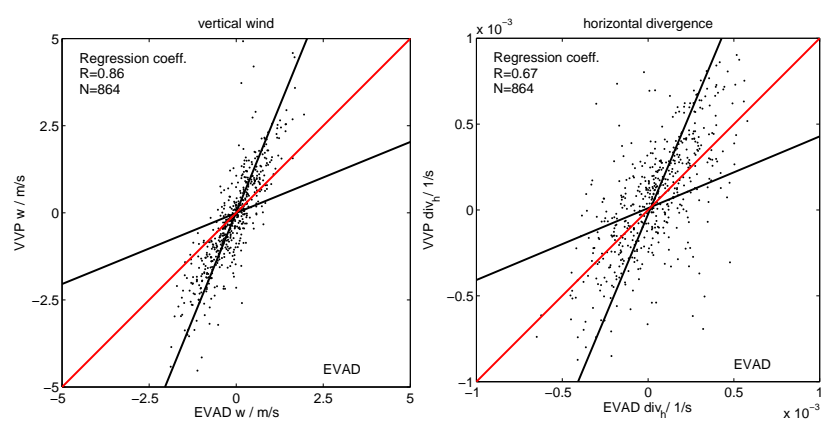

Fig. 8. Scatter plots and correlation coefficients for the vertical wind velocity and horizontal divergence applying a VVP and an EVAD analysis to the measurements. The correlation coefficient and the number of data points are given by the capital letters $R$ and $N$, respectively.

values. A comparison of the shearing and stretching deformation leads to similar results (data not shown).

The comparison between the VVP and EVAD winds and first-order inhomogeneities demonstrates that both techniques are in excellent agreement concerning the mean wind components and are able to determine first-order inhomogeneities with reasonable agreement. Considering these results it is not possible to make any statement as to which method would be more preferable to determine the wind field. Both methods have advantages and disadvantages. However, for the gravity wave analysis in the following sections all available beam directions are used, so for this analysis we preferred the VVP technique.

\section{Simulation of the quasi-simultaneous scans}

Another critical issue related to the here applied VVP is the experiment time. To gather a complete scan of 97 different beam directions MAARSY needs almost $2 \mathrm{~min}$. This overall time includes the experiment running time plus some time to upload the transceiver settings for the next experiment. This introduces a time shift between each sub-experiment of the sequence that has to be taken into account when analyzing short-period GW, which can propagate at relatively high phase speeds.

To investigate the horizontal variability of the wind field we developed an imaging technique similar to the $\mathrm{OH}$ emission observations (e.g., Suzuki et al., 2010). Considering the approach of Browning and Wexler (1968), the wind 
field is decomposed into mean winds and the first-order gradient wind terms from Eq. (1), which are related to largescale GW. "Large" refers here to the horizontal extension of the observation volume. These waves have horizontal wavelengths much larger than the scanning diameter and periods of several hours. Applying a VVP analysis permits to determine the mean prevailing wind and these first-order inhomogeneities. Hence, we can rewrite Eq. (2) and express the radial wind velocity for each azimuth and off-zenith angle by a mean zonal $\left(u_{0}\right)$, meridional $\left(v_{0}\right)$ and vertical $\left(w_{0}\right)$ wind velocity and the large-scale GW denoted by $u^{\prime}, v^{\prime}$ and $w^{\prime}$ :

$$
\begin{aligned}
\operatorname{vrad}_{\mathrm{VVP}}(\phi, \theta) & =u_{0} \cdot \cos (\phi) \sin (\theta)+v_{0} \cdot \sin (\phi) \sin (\theta) \\
& +w_{0} \cdot \cos (\theta)+u^{\prime} \cdot \cos (\phi) \sin (\theta) \\
& +v^{\prime} \cdot \sin (\phi) \sin (\theta)+w^{\prime} \cdot \cos (\theta)
\end{aligned}
$$

The variables $u^{\prime}, v^{\prime}$ and $w^{\prime}$ refer to the gradient wind terms and their absolute values depend on the position inside the measurement volume $\left(u^{\prime}, v^{\prime}, w^{\prime}\right)(\phi, \theta)$. On the other hand MAARSY measures the radial wind velocity for each beam direction, which contains contributions of the mean prevailing wind and a superposition of large-scale and small-scale waves given by $u^{\prime \prime}, v^{\prime \prime}$ and $w^{\prime \prime}$ :

$$
\begin{aligned}
\operatorname{vrad}_{\text {meas }}(\phi, \theta) & =u_{0} \cdot \cos (\phi) \sin (\theta)+v_{0} \cdot \sin (\phi) \sin (\theta) \\
& +w_{0} \cdot \cos (\theta)+u^{\prime} \cdot \cos (\phi) \sin (\theta) \\
& +v^{\prime} \cdot \sin (\phi) \sin (\theta)+w^{\prime} \cdot \cos (\theta) \\
& +u^{\prime \prime} \cdot \cos (\phi) \sin (\theta)+v^{\prime \prime} \cdot \sin (\phi) \sin (\theta) \\
& +w^{\prime \prime} \cdot \cos (\theta)
\end{aligned}
$$

In Eq. (4) the parameter $\operatorname{vrad}_{\text {meas }}$ represents the actually measured radial velocity, which contains contributions of all waves and wind field distortions. By subtracting Eq. (3) from Eq. (4) for each beam direction we obtain the radial velocity variation inside the observation volume. In order to generate an image of these radial wind variations, all 97 different beam directions are interpolated to a grid with a horizontal resolution of $250 \mathrm{~m}$ using a cubic spline, which results in a radial velocity variation image similar to the horizontally resolved RTI images shown in Fig. 4.

In order to test our decomposition of the wind field, we introduce a simple atmospheric model similar to Fritts et al. (2010a). The model assumes a mean background wind field including also the first-order wind gradient terms (e.g., horizontal divergence, stretching and shearing deformation) on which we superimpose monochromatic gravity waves with different phase velocities, wind amplitudes, wavelengths and periods. Further, we assume that the GW behave according to linear theory. The zonal, meridional and vertical wind distortions (amplitudes) are linked by the polarization relations of the GW (e.g., Fritts and Alexander, 2003).

The simulated GW properties were selected to be representative of the gravity waves that one could expect at Andenes. Nielsen et al. (2006) analyzed short-period gravity waves over Northern Norway using $\mathrm{OH}, \mathrm{Na}$ and $\mathrm{O}_{2}$ emission as well as meteor radar wind measurements from Andøya and Esrange. The observed GW showed horizontal wavelengths between $10-42 \mathrm{~km}$ and phase speeds of $29-72 \mathrm{~m} \mathrm{~s}^{-1}$. The intrinsic periods of the GW were determined to be in the range of 8-24 min. Pautet et al. (2011) investigated GW by using NLC as a tracer of the dynamics. These observations were carried out from Stockholm $\left(59.4^{\circ} \mathrm{N}\right)$. Although there is no absolute spatial coincidence between the observation volumes, these GW observations from NLC provide at least an idea of the GW properties that one could expect to measure at Andenes $\left(69.3^{\circ} \mathrm{N}\right)$ during the summer months. Pautet et al. (2011) found a variation of the phase velocities between $10-60 \mathrm{~m} \mathrm{~s}^{-1}$ for most of the observed GWs and horizontal wavelengths in the range of $10-40 \mathrm{~km}$.

In addition we considered that there is a small time shift between each experiment and investigated the effect on the radial velocity variation image and whether the general GW properties are preserved by the quasi-simultaneous multibeam experiments. Therefore we conducted two simulations assuming 25 and $125 \mathrm{~s}$ observation time between each experiment, which means that a complete scan consisting of 97 beam positions takes 100 or $500 \mathrm{~s}$, respectively. The actual measurement time for each experiment was 20.48 s plus a few seconds for updating of all the transceiver modules for the next experiment (uploading new phases for the new beam positions of the next experiment). Thus the $25 \mathrm{~s}$ case is a good approximation of the multi-beam observations conducted with MAARSY, which means it takes approximately $100 \mathrm{~s}$ to measure one complete radial velocity variation image consisting of all 97 beam directions.

To test if there is a critical effect of a sampling delay between the quasi-simultaneous experiments we assume a mean prevailing wind and the first-order inhomogeneities to be in a similar range to our observations. To ensure a good visibility of the GW the first-order wind gradient terms are removed from the images using the suggested decomposition of the wind field. The gravity wave properties are given in Table 2. In Fig. 9 the horizontal wind variability for the two test cases is shown. Figure 9a and c visualize the horizontal structure of the zonal wind and superimposed GW1 and GW2. Figure $9 b$ and $d$ represent radial velocity variation images based on the above outlined procedure. As indicated by Fig. 9a and b, a time delay of $25 \mathrm{~s}$ is not critical and the GW properties remain preserved in the radial velocity variation image. Assuming a $125 \mathrm{~s}$ time shift between each successive experiment leads to a deformation of the GW phase lines due to the then too slow sampling of the image. The GW structure appears to be bent and the wave structure is no longer preserved. For this case the phase velocity of the GW1 of $45 \mathrm{~m} \mathrm{~s}^{-1}$ is too fast to still be resolved using an observation configuration of four sub-experiments with a $125 \mathrm{~s}$ measurement time each.

The propagation of two superimposed GW within the field of view was also investigated using the same GW properties as above (Table 2). The temporal resolution between the 
a)

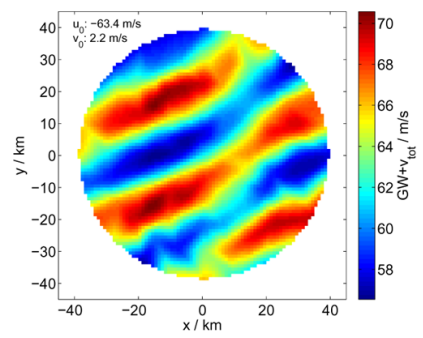

c)

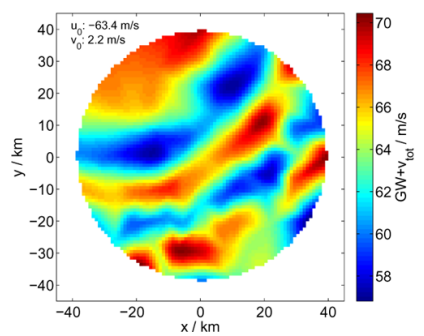

b)

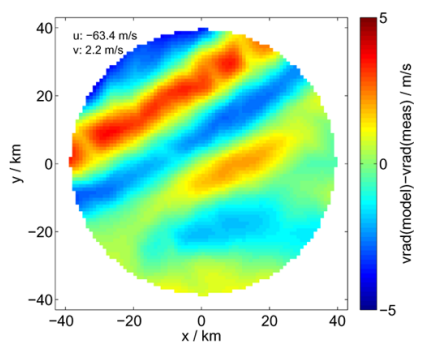

d)

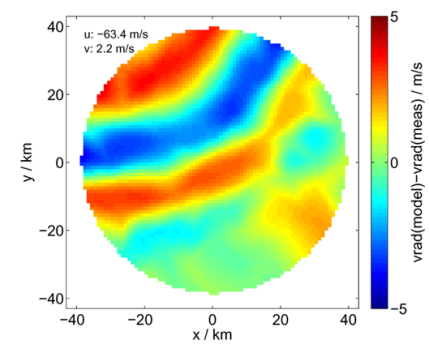

Fig. 9. Simulation of prevailing wind and superimposed gravity waves considering the sampling time of the multi-beam experiments. (a) shows mean wind plus gravity waves for a $25 \mathrm{~s}$ time shift for each experiment. (b) indicates radial velocities after subtracting the mean winds. (c) and (d) are computed assuming the same prevailing wind and gravity waves, but for a time shift of $125 \mathrm{~s}$ between the experiments.

images was $5 \mathrm{~min}$. Based on the introduced model, it is possible to simulate the temporal evolution of the GW considering different time resolutions. This procedure allows to determine the fastest resolvable phase speeds before the sampling time creates an ambiguity concerning the phase speed and propagation direction. In Fig. 10 a time series of four radial velocity variation images with a $5 \mathrm{~min}$ temporal resolution is shown, which corresponds to the MAARSY multi-beam observations. The images clearly indicate a propagation of the phase lines for both GW. For this case the propagation direction is unambiguously resolvable. The intrinsic period of $15 \mathrm{~min}$ used for the simulation is almost the lower limit. For GW with shorter periods it is hard to determine the phase speed and direction unambiguously.

Considering the results of the simulations, the MAARSY multi-beam observations are suitable to detect GW with similar properties as observed by Nielsen et al. (2006) and Pautet et al. (2011). This demonstrates that it should be possible to resolve GW from the radial velocity images and to determine the GW properties. Further it is possible to determine the direction of propagation and phase speed of the GW using a temporal resolution of $5 \mathrm{~min}$. However, a better temporal resolution than $5 \mathrm{~min}$, which corresponds approximately to the buoyancy frequency in the mesosphere, would be desirable.
Table 2. Gravity wave parameters used for the simulation. Here $\lambda_{\mathrm{h}}$ and $\lambda_{\mathrm{z}}$ denote the horizontal and vertical wavelength of the GW, respectively.

\begin{tabular}{lll}
\hline Parameter & GW1 & GW2 \\
\hline$\lambda_{\mathrm{h}}$ & $27 \mathrm{~km}$ & $34 \mathrm{~km}$ \\
$\lambda_{\mathrm{z}}$ & $18.7 \mathrm{~km}$ & $14.7 \mathrm{~km}$ \\
propagation direction & $330.0^{\circ}$ & $184.6^{\circ}$ \\
intrinsic period & $15 \mathrm{~min}$ & $15 \mathrm{~min}$ \\
phase speed & $45 \mathrm{~m} \mathrm{~s}^{-1}$ & $37.77 \mathrm{~m} \mathrm{~s}^{-1}$ \\
amplitude & $5.0 \mathrm{~m} \mathrm{~s}^{-1}$ & $2.0 \mathrm{~m} \mathrm{~s}^{-1}$ \\
\hline
\end{tabular}

a)

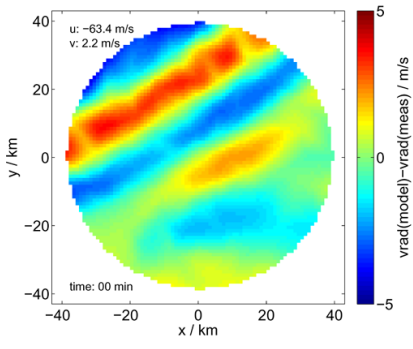

c)

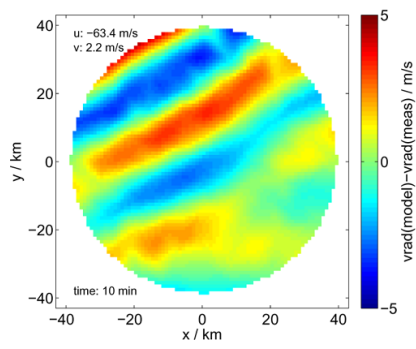

b)

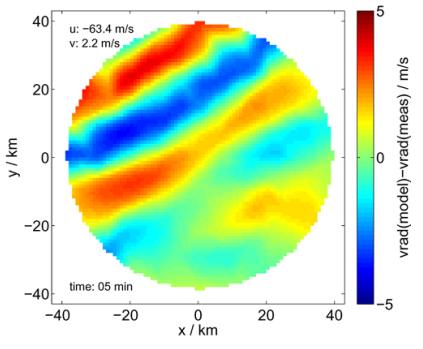

d)

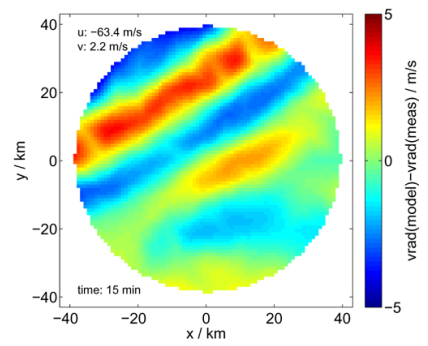

Fig. 10. Simulation of radial velocity variation images computed using a superposition of two GW. The temporal evolution of the field of view is shown in (a)-(d). The temporal resolution is $5 \mathrm{~min}$.

\section{Extracting GW parameters from horizontally resolved radial velocity images}

Considering the results of the analysis procedure with the synthetic data, the algorithm was applied to the MAARSY observations carried out on the 20 and 22 July 2011. The wind field was analyzed using the VVP technique. The corresponding wind variation images were computed decomposing the wind field according to Eqs. (3) and (4).

In a first step the radial velocity measurements were interpolated to a Cartesian grid centered at the radar site $(42 \times 42 \mathrm{~km})$ at $83.4 \mathrm{~km}$ for the $x$ and $y$ axes using a cubic spline. The grid resolution is $250 \mathrm{~m}$. We only considered times when we received a sufficient SNR $(\mathrm{SNR}>3 \mathrm{~dB})$ from all 97 beam directions at $83.4 \mathrm{~km}$ using a $2.4 \mathrm{~km}$ vertical window to account for the vertical smearing of the $25^{\circ}$ off-zenith beam. The time resolution between the measured radial velocity variation images is $5 \mathrm{~min}$. 
Table 3. Determined gravity wave parameters estimated from the radial wind variation images. Here $c$ denotes the intrinsic phase speed, $\lambda_{\mathrm{h}}$ the horizontal wavelength and "az" the azimuth angle of the propagation direction.

\begin{tabular}{lllll}
\hline date and time & $\lambda_{\mathrm{h}}$ & \multicolumn{1}{c}{$c$} & \multicolumn{1}{c}{ az } & duration \\
\hline 20 July 2011, 05:10 UTC & $28 \pm 3 \mathrm{~km}$ & $77 \pm 10 \mathrm{~m} \mathrm{~s}^{-1}$ & $330.0^{\circ}$ & $30 \mathrm{~min}$ \\
20 July 2011, 06:20 UTC & $24 \pm 5 \mathrm{~km}$ & $43 \pm 7 \mathrm{~m} \mathrm{~s}^{-1}$ & $229.6^{\circ}$ & $20 \mathrm{~min}$ \\
20 July 2011, 22:30 UTC & $47 \pm 6 \mathrm{~km}$ & $15 \pm 2 \mathrm{~m} \mathrm{~s}^{-1}$ & $292.8^{\circ} / 112.8^{\circ}$ & $20 \mathrm{~min}$ \\
22 July 2011, 11:10 UTC & $23 \pm 3 \mathrm{~km}$ & $12 \pm 3 \mathrm{~m} \mathrm{~s}^{-1}$ & $332.4^{\circ} / 152.4^{\circ}$ & $15 \mathrm{~min}$ \\
\hline
\end{tabular}

To investigate the GW activity only radial velocity variation images with all 97 beam directions were searched for events with one dominating monochromatic GW. In Fig. 11 the radial velocity images of three successive scans show the huge horizontal variability inside the measurement volume. Further, it seems that there is a wave-like structure, which is assumed to correspond to phase lines of a monochromatic gravity wave. The phase lines of the GW are indicated by black lines. The dashed lines in Fig. 11b and c represent the position of the GW phase lines of the radial velocity variation image measured at 06:25 UTC (20 July 2011). The solid lines indicate the phase lines at the time of the radial velocity variation image. The SNR 3-D structure of the PMSE for this wave is shown in Fig. 4.

The GW parameters are extracted by analyzing these images by hand considering the geometry. The phase speed is determined by averaging the horizontal differences between several phase lines (solid and dashed). The direction of propagation of the gravity wave is given by the angle of the phase line to the $x$ axis or $y$ axis. The horizontal wavelength of the GW is obtained by determining the horizontal distance between the phase lines in each image.

In total we were able to identify four events with a dominating monochromatic GW that lasted at least over a period of $15 \mathrm{~min}$ and had almost constant properties (e.g., horizontal wavelength, phase speed and propagation direction) over this period. In Table 3 the GW parameters from all four examples are summarized. However, in some cases it was not possible to resolve the direction of propagation unambiguously due to the temporal resolution of $5 \mathrm{~min}$ between the radial velocity variation images. For those events the phase lines did not show a progression between the successive pictures, which either means that the wave did not propagate or that the GW propagated within 5 min by a horizontal distance that corresponds approximately to the horizontal wavelength. Figure 12 visualizes the observed propagation directions for all four GW events. For the cases with an unambiguously determined propagation direction both possibilities are included in the polar diagram. However, the four events are not sufficient to draw conclusions about a likely source of these waves or to speculate about the "typical" GW properties yet. However, the radial velocity images seem to be suitable to gather valuable information about the horizontal wind variability inside the measurement volume that is resolvable a)
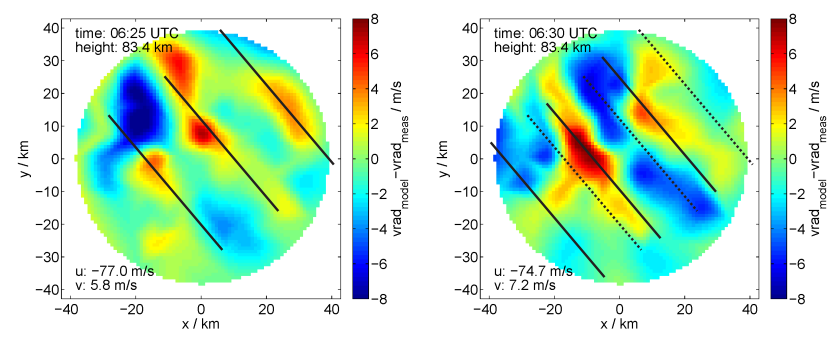

c)

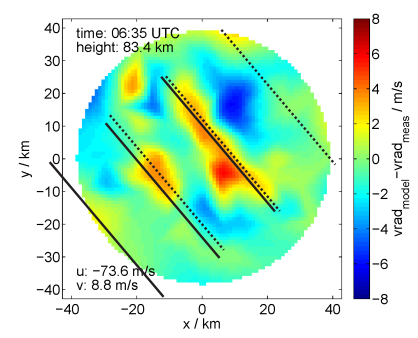

Fig. 11. Remaining horizontally resolved radial wind variation images indicating a dominating monochromatic gravity wave over a period of $15 \mathrm{~min}$. This GW event was recorded on 20 July 2011. The black lines indicate the phase lines assuming a monochromatic GW.

with such a quasi-simultaneous multi-beam experiment and to gather the GW properties.

A comparison of the here obtained results to Nielsen et al. (2006), who also presented observations above Northern Norway, shows reasonable agreement concerning the horizontal wavelengths, which took values between $10-42 \mathrm{~km}$. The intrinsic phase speeds presented in Nielsen et al. (2006), ranging from $0-80 \mathrm{~m} \mathrm{~s}^{-1}$, are in a remarkable agreement with the here determined phase speeds ranging between 12$77 \mathrm{~m} \mathrm{~s}^{-1}$. Further, the winter measurements showed mainly southward propagating GW, whereas the MAARSY summer observations reveal also northward propagating GW. These differences are likely related to the seasonal pattern of the background wind field. A comparison to the GW properties analyzed from noctilucent clouds (NLC) observed from Stockholm (Pautet et al., 2011) indicates an even better agreement concerning the observed range of horizontal wavelengths and phase speeds. 


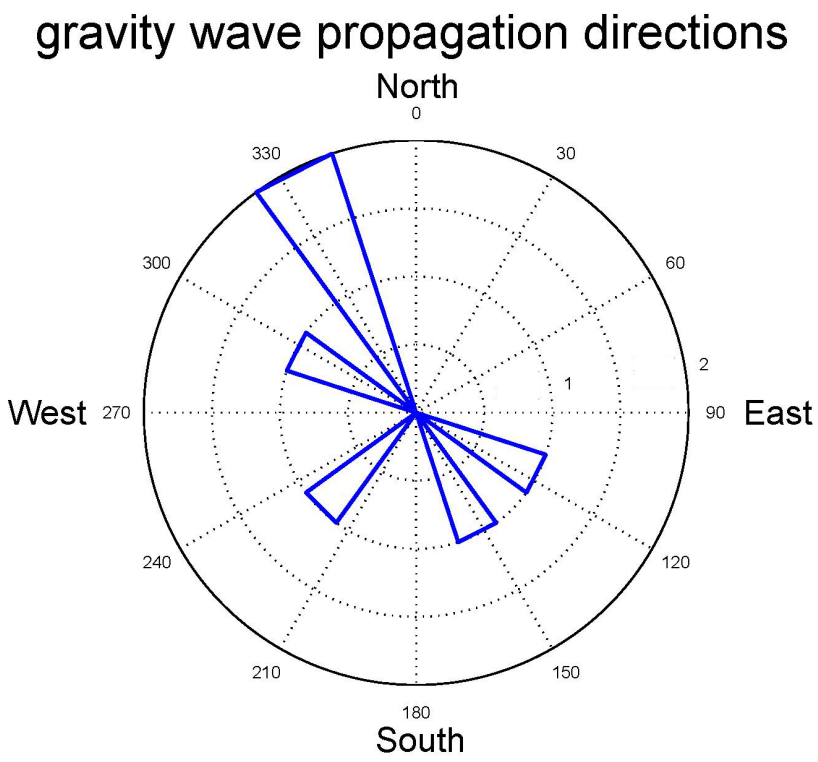

Fig. 12. Polar diagram of gravity wave propagation directions. The radial scale denotes the number of events per angular bin.

\section{Conclusions}

In this study we presented mesospheric measurements conducted with MAARSY from the summer campaign in 2011. This summer campaign demonstrates the capability of MAARSY to perform systematic scans at mesospheric heights consisting of several multi-beam experiments leading to a total number of 97 different beam directions. The observations show the 3-D variability of PMSE backscatter on horizontal scales of a few kilometers and on time scales of $5 \mathrm{~min}$. The quasi-simultaneous scanning experiments permit to apply more sophisticated wind analysis methods such as VAD and VVP (Browning and Wexler, 1968; Waldteufel and Corbin, 1979).

The comparison between both methods reveals that the VVP and VAD/EVAD horizontal wind components are in excellent agreement. Further, we find a still reasonable agreement for the vertical wind velocity and the horizontal divergence. The comparison between the different sampling volumes (VAD scans for different off-zenith angles vs. VVP) implies that one should always consider the spatial sampling volume when comparing different observation techniques. In addition the ability to determine first-order inhomogeneities could further improve our understanding of how different observation methods should be compared, in particular if the observation volumes are different or the instruments are spatially separated.

Based on the Taylor series approach from Browning and Wexler (1968) it is possible to decompose the wind field into mean prevailing winds, large-scale waves (larger than the observation volume) and small-scale variability (smaller than the observation volume), as outlined in this study. By separating the contribution of the mean prevailing wind and the large-scale waves for each radial velocity measurement, one obtains the radial velocity residuum for each beam direction, which is finally interpolated to yield a radial velocity variation image.

The introduced atmospheric model was used to investigate how the images should be composed out of a sequence of several sub-experiments and which temporal resolution is required to resolve short-period GW. Further, it was possible to test the decomposition of the wind field using synthetic data to investigate whether the GW properties were preserved within the radial velocity variation images. Our analysis shows that the outlined imaging technique permits to extract the GW properties for monochromatic waves similar to airglow observations (e.g., Nielsen et al., 2006; Suzuki et al., 2007).

Finally, two days with a strong and long-lasting PMSE were analyzed and inspected for GW events. In total we found four cases with a dominating monochromatic GW within the investigated period. The obtained GW parameters are in reasonable agreement with the results presented in Nielsen et al. (2006), Suzuki et al. (2007) and Pautet et al. (2011). The radial velocity variation images demonstrate the capability of MAARSY to resolve horizontal structures in the wind field down to a wavelength scale of $7-10 \mathrm{~km}$ with a temporal resolution of $5 \mathrm{~min}$.

Here we present a first case study to visualize the horizontal variability of the PMSE backscatter in the mesosphere at $83.4 \mathrm{~km}$. In particular, the horizontal variability of the wind field provides a new insight into the MLT dynamics on spatial and temporal scales that were so far unresolvable. The possibility to retrieve inhomogeneities in the horizontal wind field and to extract horizontally resolved short-period GW properties is essential to understand the MLT dynamics on scales of a few kilometers and minutes. This is especially of importance when comparing different measurement techniques like, e.g., lidars or other radars employing a much smaller number of beam pointing directions to determine the wind field.

Acknowledgements. The technical support by the Andøya Rocket Range is acknowledged. We also thank the technical staff of the IAP for maintaining the radar hardware and keeping MAARSY operational.

Edited by: A. Stoffelen

\section{References}

Becker, E.: Dynamical Control of the Middle Atmosphere, Space Sci. Rev., 168, 283-314, doi:10.1007/s11214-011-9841-5, 2012.

Browning, K. and Wexler, R.: The Determination of Kinematic Properties of a Wind field Using Doppler Radar, J. Appl. Meteorol., 7, 105-113, 1968. 
Chen, J.-S., Hoffmann, P., Zecha, M., and Hsieh, C.-H.: Coherent radar imaging of mesosphere summer echoes: Influence of radar beam pattern and tilted structures on atmospheric echo center, Radio Sci., 43, RS1002, doi:10.1029/2006RS003593, 2008.

Chilson, P. B., Yu, T.-Y., Palmer, R. D., and Kirkwood, S.: Aspect sensitivity measurements of polar mesosphere summer echoes using coherent radar imaging, Ann. Geophys., 20, 213-223, doi:10.5194/angeo-20-213-2002, 2002.

Dalin, P., Kirkwood, S., Hervig, M., Mihalikova, M., Mikhaylova, D., Wolf, I., and Osepian, A.: Wave influence on polar mesosphere summer echoes above Wasa: experimental and model studies, Ann. Geophys., 30, 1143-1157, doi:10.5194/angeo-301143-2012, 2012.

Eckermann, S. D. and Vincent, R. A.: Falling sphere observations of anisotropic gravity wave motions in the upper stratosphere over Australia, Pure Appl. Geophys., 130, 509-532, doi:10.1007/BF00874472, 1989.

Ern, M., Preusse, P., Alexander, M. J., and Warner, C. D.: Absolute values of gravity wave momentum flux derived from satellite data, J. Geophys. Res.-Atmos., 109, D20103, doi:10.1029/2004JD004752, 2004.

Ern, M., Preusse, P., Gille, J. C., Hepplewhite, C. L., Mlynczak, M. G., Russell, J. M., and Riese, M.: Implications for atmospheric dynamics derived from global observations of gravity wave momentum flux in stratosphere and mesosphere, J. Geophys. Res.-Atmos., 116, D19107, doi:10.1029/2011JD015821, 2011

Fritts, D. and Alexander, M. J.: Gravity wave dynamics and effects in the middle atmosphere, Rev. Geophys., 41, 1-64, doi:10.1029/2001RG000106, 2003.

Fritts, D., Hoppe, U.-P., and Inhester, B.: A study of the vertical motion field near the high-latitude summer mesopause during MAC/SINE, J. Atmos. Terr. Phys., 52, 927-938, doi:10.1016/0021-9169(90)90025-I, 1990.

Fritts, D. C., Janches, D., and Hocking, W. K.: Southern Argentina Agile Meteor Radar: Initial assessment of gravity wave momentum fluxes, J. Geophys. Res.-Atmos., 115, D19123, doi:10.1029/2010JD013891, 2010a.

Fritts, D. C., Janches, D., Iimura, H., Hocking, W. K., Mitchell, N. J., Stockwell, R. G., Fuller, B., Vandepeer, B., Hormaechea, J., Brunini, C., and Levato, H.: Southern Argentina Agile Meteor Radar: System design and initial measurements of largescale winds and tides, J. Geophys. Res.-Atmos., 115, D18112, doi:10.1029/2010JD013850, 2010b.

Gerding, M., Höffner, J., Lautenbach, J., Rauthe, M., and Lübken, F.-J.: Seasonal variation of nocturnal temperatures between 1 and $105 \mathrm{~km}$ altitude at $54^{\circ} \mathrm{N}$ observed by lidar, Atmos. Chem. Phys., 8, 7465-7482, doi:10.5194/acp-8-7465-2008, 2008.

Hocking, W. K.: A new approach to momentum flux determinations using SKiYMET meteor radars, Ann. Geophys., 23, 2433-2439, doi:10.5194/angeo-23-2433-2005, 2005.

Hoffmann, P., Rapp, M., Fiedler, J., and Latteck, R.: Influence of tides and gravity waves on layering processes in the polar summer mesopause region, Ann. Geophys., 26, 4013-4022, doi:10.5194/angeo-26-4013-2008, 2008.

Hoffmann, P., Becker, E., Singer, W., and Placke, M.: Seasonal variation of mesospheric waves at northern middle and high latitudes, J. Atmos. Sol.-Terr. Phy., 72, 1068-1079, doi:10.1016/j.jastp.2010.07.002, 2010.
Hoffmann, P., Rapp, M., Singer, W., and Keuer, D.: Trends of mesospheric gravity waves at northern middle latitudes during summer, J. Geophys. Res., 116, D00P08, doi:10.1029/2011JD015717, 2011.

Hoppe, U.-P. and Fritts, D. C.: High-resolution measurements of vertical velocity with the European incoherent scatter VHF radar: 1. Motion field characteristics and measurement biases, J. Geophys. Res.-Atmos., 100, 16813-16825, doi:10.1029/95JD01466, 1995.

Larsen, M., Fukao, S., Aruga, O., Yamanaka, M., Tsuda, T., and Kato, S.: A Comparison of VHF Radar Vertical-Velocity Measurements by a Direct Vertical-Beam Method and by a VAD Technique, J. Atmos. Ocean. Tech., 8, 766-776, 1991.

Latteck, R., Singer, W., Rapp, M., and Renkwitz, T.: MAARSY the new MST radar on Andøya/Norway, Adv. Radio Sci., 8, 219 224, doi:10.5194/ars-8-219-2010, 2010.

Latteck, R., Singer, W., Rapp, M., Vandepeer, B., Renkwitz, T., Zecha, M., and Stober, G.: MAARSY: The new MST radar on Andøya-System description and first results, Radio Sci., 47, RS1006, doi:10.1029/2011RS004775, 2012.

Matejka, T. and Srivastava, R. C.: An Improved Version of the Extended Velocity-Azimuth Display Analysis of Single-Doppler Radar Data, J. Atmos. Ocean. Tech., 8, 453-466, 1991.

Morris, R., Murphy, D., Vincent, R., Holdsworth, D., Klekociuk, A., and Reid, I.: Characteristics of the wind, temperature and PMSE field above Davis, Antarctica, J. Atmos. Sol.-Terr. Phys., 68, 418-435, doi:10.1016/j.jastp.2005.04.011, 2006.

Nakamura, T., Higashikawa, A., Tsuda, T., and Matsushita, Y.: Seasonal variations of gravity wave structures in $\mathrm{OH}$ airglow with a CCD imager at Shigaraki, Earth Planet. Space, 51, 897-906, 1999.

Nicolls, J. M., Heinselman, C. J., Hope, E. A., Ranjan, S., Kelley, M. C., and Kelly, J. D.: Imaging of Polar Mesosphere Summer Echoes with the $450 \mathrm{MHz}$ Poker Flat Advanced Modular Incoherent Scatter Radar, Geophys. Res. Lett., 34, L20102, doi:10.1029/2007GL031476, 2007.

Nicolls, M. J., Varney, R. H., Vadas, S. L., Stamus, P. A., Heinselman, C. J., Cosgrove, R. B., and Kelley, M. C.: Influence of an inertia-gravity wave on mesospheric dynamics: A case study with the Poker Flat Incoherent Scatter Radar, J. Geophys. Res.Atmos, 115, D00N02, doi:10.1029/2010JD014042, 2010.

Nicolls, M. J., Fritts, D. C., Janches, D., and Heinselman, C. J.: Momentum flux determination using the multi-beam Poker Flat Incoherent Scatter Radar, Ann. Geophys., 30, 945-962, doi:10.5194/angeo-30-945-2012, 2012.

Nielsen, K., Taylor, M. J., Pautet, P.-D., Fritts, D. C., Mitchell, N., Beldon, C., Williams, B. P., Singer, W., Schmidlin, F. J., and Goldberg, R. A.: Propagation of short-period gravity waves at high-latitudes during the MaCWAVE winter campaign, Ann. Geophys., 24, 1227-1243, doi:10.5194/angeo-241227-2006, 2006.

Pautet, D. and Moreels, G.: Ground-Based Satellite-Type Images of the Upper-Atmosphere Emissive Layer, Appl. Optics, 41, 823831, doi:10.1364/AO.41.000823, 2002.

Pautet, P.-D., Stegman, J., Wrasse, C., Nielsen, K., Takahashi, H., Taylor, M., Hoppel, K., and Eckermann, S.: Analysis of gravity waves structures visible in noctilucent cloud images, J. Atmos. Sol.-Terr. Phys., 73, 2082-2090, doi:10.1016/j.jastp.2010.06.001, 2011. 
Placke, M., Hoffmann, P., Becker, E., Jacobi, C., Singer, W., and Rapp, M.: Gravity wave momentum fluxes in the MLT - Part II: Meteor radar investigations at high and midlatitudes in comparison with modeling studies, J. Atmos. Solar-Terr. Phys., 73, 911920, doi:10.1016/j.jastp.2010.05.007, 2011.

Placke, M., Hoffmann, P., Gerding, M., Becker, E., and Rapp, M.: Testing linear gravity wave theory with simultaneous wind and temperature data from the mesosphere, J. Atmos. Solar-Terr. Phys., 93, 57-69, doi:10.1016/j.jastp.2012.11.012, 2013.

Preusse, P., Eckermann, S. D., and Offermann, D.: Comparison of global distributions of zonal-mean gravity wave variance inferred from different satellite instruments, Geophys. Res. Lett., 27, 3877-3880, doi:10.1029/2000GL011916, 2000.

Rapp, M. and Lübken, F.-J.: Polar mesosphere summer echoes (PMSE): Review of observations and current understanding, Atmos. Chem. Phys., 4, 2601-2633, doi:10.5194/acp-4-2601-2004, 2004.

Rapp, M., Latteck, R., Stober, G., Hoffmann, P., Singer, W., and Zecha, M.: First three-dimensional observations of polar mesosphere winter echoes: Resolving space-time ambiguity, J. Geophys. Res.-Space, 116, A11307, doi:10.1029/2011JA016858, 2011.

Rauthe, M., Gerding, M., Höffner, J., and Lübken, F.-J.: Lidar temperature measurements of gravity waves over Kühlungsborn $\left(54^{\circ} \mathrm{N}\right)$ from 1 to $105 \mathrm{~km}$ : A winter-summer comparison, J. Geophys. Res.-Atmos., 111, D24108, doi:10.1029/2006JD007354, 2006.

Rüster, R., Röttger, J., Schmidt, G., Czechowsky, P., and Klostermeyer, J.: Observations of mesospheric summer echoes at VHF in the polar cap region, Geophys. Res. Lett., 28, 1471-1474, doi:10.1029/2000GL012077, 2001.

Smirnova, M., Belova, E., Kirkwood, S., and Mitchell, N.: Polar mesosphere summer echoes with ESRAD, Kiruna, Sweden: Variations and trends over 1997-2008, J. Atmos. Solar-Terr. Phys., 72, 435-447, 2010.

Smirnova, M., Belova, E., and Kirkwood, S.: Aspect sensitivity of polar mesosphere summer echoes based on ESRAD MST radar measurements in Kiruna, Sweden in 1997-2010, Ann. Geophys., 30, 457-465, doi:10.5194/angeo-30-457-2012, 2012.
Stober, G., Latteck, R., Rapp, M., Singer, W., and Zecha, M.: MAARSY - the new MST radar on Andøya: first results of spaced antenna and Doppler measurements of atmospheric winds in the troposphere and mesosphere using a partial array, Adv. Radio Sci., 10, 291-298, doi:10.5194/ars-10-291-2012, 2012.

Strelnikova, I. and Rapp, M.: Majority of PMSE spectral widths at UHF and VHF are compatible with a single scattering mechanism, J. Atmos. Sol.-Terr. Phys., 73, 2142-2152, doi:10.1016/j.jastp.2010.11.025, 2011.

Strelnikova, I. and Rapp, M.: Statistical characteristics of PMWE observations by the EISCAT VHF radar, Ann. Geophys., 31, 359-375, doi:10.5194/angeo-31-359-2013, 2013.

Suzuki, S., Shiokawa, K., Otsuka, Y., Ogawa, T., and Wilkinson, P.: Statistical characteristics of gravity waves observed by an allsky imager at Darwin, Australia, J. Geophys. Res., 109, D20S07, doi:10.1029/2003JD004336, 2004.

Suzuki, S., Shiokawa, K., Otsuka, Y., Ogawa, T., Kubota, M., Tsutsumi, M., Nakamura, T., and Fritts, D. C.: Gravity wave momentum flux in the upper mesosphere derived from $\mathrm{OH}$ airglow imaging measurements, Earth Planet. Space, 59, 421-428, 2007.

Suzuki, S., Nakamura, T., Ejiri, M. K., Tsutsumi, M., Shiokawa, K., and Kawahara, T. D.: Simultaneous airglow, lidar, and radar measurements of mesospheric gravity waves over Japan, J. Geophys. Res.-Atmos., 115, D24113, doi:10.1029/2010JD014674, 2010.

Theuerkauf, A., Gerding, M., and Lübken, F.-J.: LITOS - a new balloon-borne instrument for fine-scale turbulence soundings in the stratosphere, Atmos. Meas. Tech., 4, 55-66, doi:10.5194/amt-4-55-2011, 2011.

Waldteufel, P. and Corbin, H.: On the Analysis of Single-Doppler Radar Data, J. Appl. Meteorol., 18, 532-542, 1979.

Zecha, M., Röttger, J., Singer, W., Hoffmann, P., and Keuer, D.: Scattering properties of PMSE irregularities and refinement of velocity estimates, J. Atmos. Solar-Terr. Phys., 63, 201-214, 2001. 